\title{
Sobre la noción de etnocidio, con especial atención al caso brasileño ${ }^{1}$
}

\author{
On the Notion of Ethnocide \\ with Emphasis on the Case of Brazil
}

\author{
Eduardo VIVEIROS DE CASTRO \\ Universidade Federal do Rio de Janeiro \\ Museu Nacional \\ ORCID: 0000-0003-4902-0574 \\ eviveirosdecastro@gmail.com
}

\section{Resumen}

El objetivo de este ensayo, escrito con fines de argumentación jurídica, es discutir el concepto de etnocidio para el caso de Brasil. El autor expone con detalle las complejas articulaciones entre las legislaciones brasileña e internacional con los conceptos de genocidio y de etnocidio. La meta es discutir las definiciones de lo indio y de lo indígena en el contexto del Brasil. ${ }^{2}$ Este ensayo retoma ideas y contenidos de artículos como "O nativo relativo" de 2002 y “Os Involuntários da Pátria. Elogio do subdesenvolvimento” de 2016.

Palabras clave: etnocidio, Brasil, indígenas, indigenismo, constitución brasileña.

${ }^{1}$ Texto traducido por Alejandro Fujigaki Lares y María Isabel Martínez Ramírez.

2 [Nota de Traductores, en adelante N. de T.] Este texto fue escrito en el 2016. Eduardo Viveiros de Castro, su autor, reflexiona críticamente sobre las políticas públicas con las que históricamente el Estado brasileño se ha relacionado con poblaciones indias y quilombolas. Hasta aquel momento, Brasil fue gobernado por el Partido del Trabajo (PT) durante trece años bajo los dos mandatos consecutivos de Luis Ignacio Lula da Silva y uno de Dilma Rouseff. Este último quedó inconcluso por la polémica destitución de Rouseff en agosto de 2016. Una de las facetas más cuestionadas de este período fue que, pese a ser gobiernos con inclinaciones de izquierda, el gobierno apoyó proyectos y megaproyectos en el rubro de agronegocios y de energía, tanto públicos como privados, que han dañado los territorios y que han perjudicado los modos de existencia de las poblaciones indígenas y quilombolas. Con todo, los problemas que enfrentan estos pueblos se han agudizado a partir de la instauración del gobierno conservador de Michel Temer (2016-2018) y del mandato ultraconservador de Jair Bolsonaro (2019 a la fecha). Las políticas públicas y las acciones gubernamentales de estos últimos años están definidas por una tendencia firme y constante para eliminar los derechos colectivos de estas poblaciones. En 2020, el contexto de las poblaciones indias y quilombolas brasileñas es sumamente adverso, pues las condiciones sociopolíticas y sanitarias se deterioraron gravemente.

Para una reflexión actual del tema desarrollado en este artículo, sugerimos consultar Martin Legros, “Eduardo Viveiros de Castro: 'Ce qui se passe au Brésil relève d'un génocide’”, Philosophie Magazine, acceso el 19 de mayo de 2020, https://www.philomag.com/articles/ eduardo-viveiros-de-castro-ce-qui-se-passe-au-bresil-releve-dun-genocide. O su traducción 


\begin{abstract}
The present essay is a discussion about the concept of ethnocide in the Brazilian context. It is aimed to explain the complex articulation of the concepts of genocide and ethnocide in the Brazilian and international laws, as well as to discern the definitions of the Indian and the indigenous in contemporary Brazil, before the start of a new wave of attacks against the rights of the Indian peoples of this country. To support this discussion, the author has retrieved the ideas and content of his own articles "O nativo relative" (2002) and "Os Involuntários da Pátria. Elogio do subdesenvolvimento" (2016).
\end{abstract}

Keywords: ethnocide, Brazil, indigenous peoples, indigenism, Brazilian Constitution.

1. Prima facie, pueden considerarse como "acción etnocida" —en lo que concierne a las minorías étnicas indígenas situadas en territorio nacionaltodas las decisiones políticas tomadas en ausencia de las instancias de formación de consenso propias de las colectividades afectadas por tal decisión; lo cual conlleva mediata o inmediatamente la destrucción del modo de vida de las colectividades o que constituye una grave amenaza (acción con potencial etnocida) para la continuidad de ese modo de vida. Es merecedor de tipificarse antropológicamente como etnocidio todo proyecto, programa o acción de gobierno o de organización civil (misiones religiosas proselitistas, por ejemplo) que viole los derechos reconocidos en el Capítulo viıI de la Constitución Federal de Brasil de 1988 ("De los Indios"), en particular pero no exclusivamente aquellos mencionados en el caput del Artículo 231, que sanciona la existencia - y por tanto el derecho a la persistencia- de "su [de los indios] organización social, costumbres, lenguas, creencias y tradiciones y el derecho originario sobre las tierras que ocupan".

2. Podríamos añadir, entre los elementos de configuración de este crimen -crimen en sentido moral o incluso formalmente jurídico-, para el caso, una vez más, de las minorías étnicas llamadas indígenas (véase adelante, Sección IX), toda acción que constituye una violación de la Resolución de las Naciones Unidas sobre los Derechos de los Pueblos Indígenas, aprobada

al español por el Observatorio Plurinacional de Aguas, "Eduardo Viveiros de Castro: lo que está pasando en Brasil es un genocidio", Observatorio Plurinacional de Aguas, acceso el 20 de mayo de 2020, https://oplas.org/sitio/2020/05/20/eduardo-viveiros-de-castro-lo-que-estapasando-en-brasil-es-un-genocidio/. 
el 13 de septiembre de 2007, en especial sus artículos 8 y 10. ${ }^{1}$ La Convención 169 de la OІт (1989), ratificada por Brasil, especifica, por su parte, los derechos de los "pueblos indígenas y tribales", y, a pesar de no mencionar -como, de hecho lo hace, la Resolución de la ONU - el término "etnocidio", deja perfectamente claro que el desacato a los derechos allí establecidos es una grave amenaza para la sobrevivencia y autonomía socioculturales de los pueblos en cuestión. ${ }^{2}$

1. El concepto de "etnocidio" tiene su origen en la obra del antropólogo francés Robert Jaulin, específicamente en su libro La paix blanche: introduction à l'ethnocide (1970), ${ }^{3}$ en el cual el autor ofrece un testimonio etnográfico detallado del proceso de destrucción de la cultura y sociedad de los bari, un pueblo habitante de la frontera venezolana-colombiana, llevado a cabo por la acción conjunta de misiones religiosas, órganos estatales (Fuerzas Armadas), corporaciones petroleras, y por las invasiones de su territorio por los miembros de las sociedades circundantes. ${ }^{4}$

2. Robert Jaulin entiende que el etnocidio no se caracteriza por los medios, sino por los fines. Éste_es un proceso que tiene como objetivo la destrucción sistemática del modo específico de vida (técnicas de subsistencia y relaciones

${ }^{1}$ Nações Unidas, Declaração das Nações Unidas sobre os Direitos dos Povos Indígenas (Río de Janeiro: Centro de Informação das Nações Unidas United Nations Information Centre-Rio de Janeiro, 2008), http://www.un.org/esa/socdev/unpfii/documents/DRIPS_ pt.pdf. N. de T. En español consúltese Comisión Nacional de los Derechos Humanos, Declaración de las Naciones Unidas sobre los Derechos de los Pueblos Indígenas (México: Comisión Nacional de los Derechos Humanos, 2018), http://www.cndh.org.mx/sites/all/doc/cartillas/2015-2016/13-declaracion-pueblos-indigenas.pdf.

${ }^{2}$ N. de T. Sobre la Convención 169, véase una breve historia de su ratificación por Brasil, Povos Indígenas No Brasil, "Convenção OIT sobre Povos Indígenas e Tribais em países independentes n. 169”, Povos Indígenas no Brasil, acceso el 19 de octubre de 2020, https:// pib.socioambiental.org/pt/C/direitos/internacional/convencao-oit-sobre-povos-indigenas-e-tribais-em-.

${ }^{3}$ N. de T. Existe edición en español Robert Jaulin, La paz blanca. Introducción al etnocidio (Buenos Aires: Tiempo Contemporáneo, 1973).

${ }^{4}$ La entrada de Wikipedia sobre el autor presenta un resumen útil del contexto en que el concepto fue formulado, y su definición básica: Wikipedia, “Robert Jaulin”, acceso el 20 de mayo de 2020, https://en.wikipedia.org/wiki/Robert_Jaulin\#The_concept_of_ethnocide. 
de producción, sistema de parentesco, organización comunitaria, lengua, costumbres y tradiciones) de los pueblos diferentes, de estos aspectos, por parte del pueblo, agencia o Estado que lleva a cabo la empresa de destrucción. Si el genocidio consiste en la eliminación física deliberada de una etnia, pueblo o población, el etnocidio persigue el "espíritu" (la moral) de un pueblo, su eliminación en cuanto colectividad sociocultural diferenciada. Naturalmente, el genocidio es uno de los medios más eficaces de cometer el etnocidio - ya que es un medio suficiente para tal fin-, pero no es un medio necesario. Además, los dos crímenes pueden combinarse, como sucedió en el caso del genocidio de los judíos (y otros “no arios", tales como los gitanos) perpetrado por el nazismo, cuando no sólo millones de seres humanos de este pueblo fueron fríamente asesinados, como todo rastro, comportamiento u objeto cultural identificado, correctamente o no, como “judío", fue prohibido u obliterado por el gobierno nazi (literatura, obras de arte, trabajos científicos, lengua, habitaciones, etcétera).

3. El asesinato "ocasional" e impune de individuos, la persecución política, la violencia y la humillación cotidianas dirigidas contra los miembros de la minoría étnica afectada, el secuestro de menores para ser adoptados o educados fuera de su ambiente cultural original, la propaganda calumniosa, el desplazamiento forzado de los territorios tradicionales, el abandono obligatorio de los usos y costumbres de la colectividad definida como objetivo, todas éstas son otras tantas formas de cometer etnocidio que, particularmente cuando los Estados nacionales están implicados, pueden ser llevados a cabo muy eficazmente por omisión: negligencia, indiferencia, apoyo oficioso, silenciamiento mediático inducido.

4. Entiendo, sin embargo, que la distinción de Jaulin entre "medios" y "fines" es engañosa, pues deja abierta la posibilidad de algo como un "etnocidio culposo" antes que "doloso"; en otras palabras, sugiere que las acciones etnocidas pueden ser cometidas como el "resultado no intencional" o el "daño colateral" de decisiones, proyectos e iniciativas de gobierno cuyo objetivo ideal no es la extinción sociocultural o desconfiguración étnica de una colectividad, sino la realización de "proyectos de desarrollo" (grandes obras de infraestructura como presas, carreteras, plantas industriales, extracción minera y petrolera) que tendrían como objetivo ostensiblemente beneficiar a toda una población nacional. Dado que las instancias del planeamiento y decisión de los Estados que sancionan e implementan tales proyectos tienen 
el deber ineludible de estar ampliamente informadas sobre los impactos locales de sus intervenciones sobre el ambiente en el que viven las poblaciones afectadas, el etnocidio es frecuentemente una consecuencia concreta y efectiva, a pesar de las intenciones proclamadas del agente etnocida, y se torna así algo tácitamente admitido, cuando no estimulado indirecta y maliciosamente (lo que configura dolo) por supuestas acciones de "mitigación" y "compensación" que, como norma general, se convierten en un instrumento eficaz en el proceso de destrucción cultural, en total contradicción con su propósito declarado de protección de los modos de vida "impactados".

1. Como observamos, el concepto de etnocidio no es mencionado directamente en los documentos diplomáticos más importantes de las últimas décadas (específicamente en la Convención 169 de la oit y la Resolución de las Naciones Unidas sobre los Derechos de los Pueblos indígenas) - como tampoco está mencionado en la Constitución Federal brasileña de 1988-. No obstante, diversas iniciativas de peso han focalizado explícitamente esta forma de destrucción de modos de vida colectiva, motivada por la diferencia de tales modos de vida, frente a las formaciones sociopolíticas dominantes. Destaca el "Encuentro de Especialistas en Etno-Desarrollo y Etnocidio en América Latina”, patrocinado por la Unesco y realizado en FLACso en Costa Rica en $1981 .^{5}$ Nuestra impresión es que el concepto camina lenta pero firmemente hacia la aceptación oficial por parte de los organismos internacionales, a pesar de la persistente presión en contracorriente ejercida por los Estados nacionales, muchos de los cuales tienen en deuda histórica y étnica una abundancia de políticas inequívocamente etnocidas, asociadas o no a las acciones genocidas. Tal deuda histórica es especialmente obvia en el caso de países emergentes de las antiguas colonias europeas en las Amé-

${ }^{5}$ Véase Facultad Latinomaricana de Ciencias Sociales y unesco, "Réunion d'experts sur l'ethno-développement et l'ethnocide en Amérique Latine, San José, 1981”, 7-11 de diciembre de 1981, Facultad Latinoamericana de Ciencias Sociales, http://unesdoc.unesco.org/ images/0005/000507/050786eb.pdf. Reuniones y resoluciones análogas fueron hechas y tomadas relativamente en otras partes del mundo donde el etnocidio es un problema gravísimo, como África. Véase Centre for the Study of African Development, "Meeting of Experts on the Study of Ethno-development and Ethnocide in Africa, Ouagadougou, 1983”, 31 de enero al 4 de febrero de 1983, Centre for the Study of African Development, http://unesdoc. unesco.org/images/0005/000557/055780EB.pdf. 
ricas, África y Oceanía. Aquellos países donde las poblaciones indígenas precoloniales fueron reducidas a la condición de minorías étnicas marginalizadas, definidas explícitamente como elementos residuales y vestigiales que deben (en los sentidos predictivo y prescriptivo) irse disolviendo en el cuerpo homogéneo de la "Nación", se han mostrado particularmente recalcitrantes en admitir su responsabilidad por las acciones etnocidas que no sólo banalizan siniestramente su historia (acciones muchas veces transmutadas en hechos y momentos históricos épicos de la construcción nacional), sino que les son, en gran medida, íntegramente consustanciales.

\section{III}

1. Una definición mínimamente exhaustiva del concepto de etnocidio depende de un consenso previo sobre el significado de la noción de ethnos, grupo o etnia. Además, la noción de "grupo étnico", en el contexto de la problemática del etnocidio, es difícilmente disociable del concepto de minoría étnica. En el caso brasileño, como en los demás territorios anexados por la expansión colonial-militar de Occidente moderno - el "nomos de la Tierra" (Carl Schmitt) ${ }^{6}$ establecido por la repartición del globo entre las potencias europeas a partir de los siglos XVI y XVII-, esa minoría étnica es paradigmáticamente definida como indígena. Será necesario entonces detenernos brevemente sobre estos tres conceptos: grupo étnico, minoría étnica, indígena.

2. Aunque existe una importante polémica, dentro de la disciplina antropológica, sobre cuál es la mejor interpretación teórica del "fenómeno étnico", ${ }^{7}$ tomamos como definición, con potencial de consenso, aquella ofrecida por Anthony D. Smith: una comunidad étnica o etnia

puede ser definida como un grupo humano cuyos miembros comparten mitos comunes de origen y descendencia, memorias históricas, valores y patrones

${ }^{6}$ N. de T. Carl Schmitt, The Nomos of the Earth in the International Law of the Jus Publicum Europaeum (Nueva York: Telos Press, 2003), publicación original de 1950.

${ }^{7}$ Cabe recordar las confrontaciones y las combinaciones complejas entre las llamadas teorías "primordialistas", "instrumentalistas" y "constructivistas" de la etnicidad. Véase la entrada Sergey Solokovskii y Valery Tishkov, "Ethnicity”, en Encyclopedia of Social and Cultural Anthropology, ed. Alan Barnard y Jonathan Spencer (Nueva York: Routledge, 1996): 190-192. 
culturales, la asociación con un territorio determinado, y un sentido de solidaridad...8

3. Pese a que todos estos criterios no se apliquen automáticamente a todas las colectividades que fueron caracterizadas, en la literatura actual, como etnia o grupo étnico, y admitiendo que pueden ser aplicados, cum grano salis, a los miembros de un Estado-nación constituido como una colectividad étnicamente homogénea - caso raro y universalmente no verificable en las Américas, excepto bajo la forma de las ideologías nacionalistas autoritarias que omiten de su "narrativa", cuando no conmemoran, sucesivos etnocidios-, tales criterios pueden aplicarse de manera razonablemente adecuada (y completa) al caso de las etnias indígenas de las Américas, de Brasil, incluso.

4. La definición de Smith, sin embargo, puede criticarse por su carácter poco dinámico, excesivamente externo u objetivista, al no contemplar los procesos históricos de constitución y especialmente de reconstitución activa de las colectividades étnicamente diferenciadas - los llamados procesos de resurgimiento o "emergencia" étnica-, esto es, de la reivindicación de continuidades memoriales y originarias interrumpidas por procesos de etnocidio que hoy se constata han sido incompletos. Esa situación es de especial relevancia en el Brasil contemporáneo, sobre todo a partir de la promulgación de la Constitución Federal de 1988, que consagró y perennizó el instituto del indigenato9 (en el cual recaen las iniciativas legislativas y las decisiones de recientes tribunales que procuran descaracterizarlo o abolirlo), cuando diversas identidades étnicas indígenas "sumergidas" comenzaron a luchar por el reconocimiento de su condición indígena ante el Estado, con las debidas consecuencias jurídicas previstas por el artículo 231 de la Constitución Federal de Brasil —en particular el derecho de tener los territorios que ocupan precariamente-, puestos a salvo del violento proceso de privatización por corporaciones agroindustriales y/o

${ }^{8}$ Anthony D. Smith, “The Politics of Culture, Ethnicity and Nationalism”, en Companion Encyclopedia of Anthropology. Humanity, Culture and Social Life, ed. Tim Ingold (Nueva York: Routledge, 1994), 706-733.

${ }^{9}$ N. de T. En Brasil, término jurídico para designar el estado o la cualidad del indígena o del indigenismo, así como el conjunto o el agrupamiento de los indígenas de una región o país. 
de la intervención socioambientalmente devastadora de los proyectos de “desarrollo" patrocinados por el Estado.

1. La situación de los pueblos indígenas en Brasil puede ser claramente caracterizada como minoritaria. Los indios en Brasil son una minoría étnica, social, cultural y política. La condición minoritaria, en este sentido, no tiene un grado cuantitativo o estatístico ${ }^{10}$-aunque tenga un sentido indisociable de su inserción en un Estado-. Pese a que la población indígena, oficial o real, sea censariamente pequeña (aunque en crecimiento, en proporción muy significativa) dentro del conjunto de la población de "ciudadanos" del Estado nacional, muchas otras minorías nacionales -raciales (negros), de género (mujeres), de orientación sexual (LGBT) y otras- están compuestas por contingentes numéricamente significativos, en algunos casos estadísticamente mayoritarios.

2. Éste es el caso, por ejemplo, del porcentaje de afrodescendientes de la población nacional, cuya condición políticamente minoritaria es reconocida de jure por las políticas de acción afirmativa de intención compensatoria, en vista de la discriminación, persistente hasta el presente, sufrida por los brasileños que trazan su ascendencia y su fenotipo (y/o los tienen trazados) hacia la diáspora africana, proceso que enlazó la esclavitud con el etnocidio deliberado - a saber, la obliteración sistemática de las solidaridades de origen de los africanos traídos a Brasil, con el objetivo de desmoralizar y controlar a la población esclava, reduciéndola a una minoría racial étnicamente indiferenciada ("negros")—.

3. La existencia de "cuotas étnicas"11 dentro del conjunto de políticas públicas de acción afirmativa (por ejemplo, en la enseñanza pública), como

${ }^{10}$ N. de T. Estatístico: de estadística y Estado. Una de las características de la escritura del autor es la creación de nuevos conceptos mediante el juego y la aglutinación de una o varias palabras. Para la traducción en español se emplean las mismas combinaciones de palabras sin colocarlas en cursivas, a menos que así aparezcan en el original. Se indica en una nota al pie los términos en cuestión.

11 N. de T. Creada en 2012, la Lei de Cotas (12.711) designó, por primera vez en la historia de Brasil, la reserva entre $10 \%$ y $50 \%$ de las matrículas en universidades e institutos 
categoría distinta de las "cuotas raciales", da testimonio de que los pueblos indígenas son reconocidos (1) como minorías étnicas, dado que otros grupos "étnicamente" distintivos del país (descendientes de colonos alemanes, italianos, japoneses, etcétera) no están incluidos en las políticas de acción afirmativa, y (2) como minorías étnicas, esto es, simultáneamente como pueblos social y culturalmente diversos entre sí y como pueblos diferenciados globalmente de una cultura dominante nacional, en la cual es pretendido incluir los aportes culturales de los inmigrantes europeos y asiáticos, como también, pero bajo un modo discriminatorio, opresivo y folclorizante ("minoritario"), la cultura y sobre todo la población de afrodescendientes. ${ }^{12}$

\section{V}

1. Las nociones de "minoría" y "minoridad" son complejas. Seguimos aquí, sinópticamente, las indicaciones de Gilles Deleuze y Félix Guattari, que en el estudio monumental de filosofía política Mil mesetas (1980) ofrecen una reflexión conceptualmente poderosa sobre estas nociones. Las ideas de "minoría" y "mayoría" (o de modos "menor" y "mayor" de declinar un contenido expresivo cualquiera, sea éste lingüístico, artístico, jurídico, político, etcétera) dependen de la oposición entre una constante y una variable,

federales para la población afrodescediente e indígena. Véase Presidência da República, "Lei $\mathrm{N}^{\mathrm{o}}$ 12.711, de 29 de agosto de 2012", acceso el 20 de mayo de 2020, http://www.planalto. gov.br/ccivil_03/_ato2011-2014/2012/lei/112711.htm.

${ }^{12}$ La distinción entre "raza" (en el sentido de discriminación racial objetiva, no en el sentido erróneo de la categoría de contenido genético-biológico) y "etnia” o, para ser más directos, entre "negros" e "indios", es inestable y mutable, dado que: (a) la tipificación aceptada, como crimen de racismo, para las violencias y las humillaciones cometidas contra indígenas motivadas por su condición de indígenas; (b) el reconocimiento constitucional de la categoría de los quilombolas, esto es, de comunidades territorializadas de afrodescendientes, que les atribuyó derechos colectivos sobre las tierras que ocupan, aunque de naturaleza distinta de los derechos territoriales indígenas; (c) la emergencia creciente de un vasto universo de comunidades y complejos culturales "afro-indígenas" diseminados por prácticamente todo el país, universo que se viene constituyendo como un nuevo actor antropológico, y verosímilmente sociopolítico, dentro de la multiplicidad de comunidades y pueblos - en el sentido lato y correcto, esto es, plural, de la expresión- que constituyen el conjunto de lo impropiamente denominado "pueblo brasileño". La ideología del "mestizaje”, eufemismo hipócrita para el proyecto secular de blanqueamiento de la nación, se disuelve a pasos agigantados, y a la espera de una reconstitución real del carácter diverso y "mayoritariamente minoritario" de las clases dominadas del país. 
y de su trascendencia mediante la noción propiamente minoritaria de variación. Resumo y parafraseo, en el párrafo siguiente, las consideraciones de Deleuze \& Guattari a ese respecto.

2. Minoría y mayoría no se oponen solamente de una manera cuantitativa. Mayoría implica una constante, algo como un patrón-estándar que le sirve de instrumento de evaluación. "Supongamos" (dicen D \& G; pero una suposición es una constatación) que la constante o patrón occidental sea algo como "hombre, blanco, macho, adulto, urbanita, heterosexual, hablante de una lengua europea 'de cultura'" - podemos agregar, en el caso brasileño: católico nominal, de clase media o alta, habitante del sur o sureste, ${ }^{13}$ de formación universitaria, con una determinada pauta de consumo y otras determinaciones fácilmente numerables-. Como observan irónicamente Deleuze y Guattari, este "hombre, blanco, etcétera" es efectivamente la Mayoría, pero él es menos numeroso que los mosquitos, las mujeres, los negros, los campesinos, los homosexuales y así sucesivamente. Él aparece, al mismo tiempo, como constante y como una variable de donde se extrae la constante. La mayoría supone un estado de poder y dominación, y no lo inverso; ésta supone el patrón-estándar y no lo inverso. Pero, por otro lado, la mayoría, en la medida en que es analíticamente comprendida a través del patrón-estándar, nunca es alguien, siempre es Nadie, "en tanto que la mayoría es el devenir <la variación, diferente de una variable> de todo mundo", ésta es su trayectoria potencial, en la medida en que todo mundo se desvía de un modo u otro del patrón-estándar. Por eso los autores distinguen entre lo mayoritario como un sistema homogéneo y constante, las minorías como subsistemas variables (incluidas y dominadas por el sistema mayoritario), y lo minoritario como devenir o trayectoria potencial, como variación continua, figura universal de la consciencia minoritaria. "Es la variación continua que constituye el devenir minoritario de todo mundo, por oposición al Hecho mayoritario de Nadie." Y como sabemos, nosotros los brasileños, somos gobernados por Nadie -incluso si los gobernantes son gobernados por el patrón-estándar de la Mayoría-. "El devenir minoritario como figura universal de la consciencia se llama autonomía."

${ }^{13}$ N. de T. La región sur o sureste es la más poblada y desarrollada económicamente de Brasil. 
3. En este sentido conceptual, cuya complejidad no tenemos espacio para desarrollar aquí, las minorías étnicas indígenas no son simplemente subconjuntos o subsistemas socioculturales "incluidos" en la Mayoría, cuya figura política por excelencia es el Estado-nación soberano, sino colectividades en un proceso incesante de minorización, de variación continua, proceso propiamente intolerable para la máquina administrativa de la Mayoría (“¿quién es indio al final?”; "pero esos tipos no son indios”; “ahora todo mundo quiere ser indio en la Amazonia”; etcétera). Por eso los procesos de "etnogénesis", de reafirmación o resurgimiento étnico que marcan la historia contemporánea se muestran tan amenazadores para los poderes constituidos y los intereses que ellos representan; por eso también los procesos de resistencia (que deberíamos escribir "rexistencia”) indígena contra las fuerzas etnocidas son afirmaciones del rechazo para dejarse capturar por los mecanismos de representación, delegación, “consentimiento informado", indemnización, planes de emergencia, programas de mitigación de impacto, conversión religiosa, inserción en el mercado de trabajo, capacitación profesional, beneficios sociales y otras tantas formas de sabotaje de la autonomía como horizonte móvil de la acción política indígena. El etnocidio, en este sentido, es más que un acto, o una serie encadenada de actos específicos, limitados en el tiempo y en el espacio, contra las minorías étnicas indígenas - es la esencia misma de la relación, de 1500 hasta los días de hoy, entre la forma-Estado (el Estado colonial, imperial y republicano) y la forma-ethnos (los pueblos indígenas) en Brasil-.

\section{VI}

1. La historia de Brasil, es innecesario recordar, es la historia de una sucesión de genocidios - de la "guerra justa" a la masacre del paralelo 11; de las expediciones punitivas de los gobiernos coloniales a las incursiones predatorias de los bandeirantes de São Paulo; de las masacres de indios en las correrias en la Amazonia occidental durante el ciclo de caucho a la limpieza étnica de los sertones del sur y sureste para la construcción de vías del tren y la implantación del asentamiento europeo; o, para tomar un ejemplo reciente, la ofensiva implacable, movida a fierro y fuego, por los hacendados del estado de Matto Grosso del Sur en contra de los guaraní-kaiowá,_configurando un panorama con diversas analogías con la situación de los palestinos en la Franja de Gaza-. Pero esa historia es también, y tal vez sobre 
todo, la historia de un programa metódico de etnocidio - de la catequesis sobre el signo de compelle intrare y "de la prédica de la espada y de la vara de fierro" (Anchieta) al reclutamiento de tropas indígenas por los sertanistas y por el ejército imperial; de las reducciones y disminuciones misioneras a la prohibición del uso de los vernáculos nativos en las aldeas y campamentos coloniales; de la imposición de una lengua franca en los siglos XVII y XVIII al secuestro, en pleno siglo xx, de hijos de los indios por las "escuelas" de los salesianos en Río Negro; de la destrucción brutal de los sacra indígenas identificados como manifestaciones del demonio al proselitismo evangélico-capitalista de los misioneros norteamericanos generosamente tolerados, cuando no acogidos, por todos nuestros gobiernos "nacionalistas" (de Vargas a Rousseff); del Derecho de Indios colonial a la creación del "Servicio de Protección a los Indios y Localización de los Trabajadores Nacionales"; ${ }^{14}$ de la Ley de Tierras de 1850 a las restricciones sofisticadas al artículo 231 aprobadas por el Supremo Tribunal Federal en el caso de Raposa-Sierra do Sol en 2013; de las invasiones por intereses mineros de la tierra yanomami a la destrucción ambiental y económica, la expulsión y reubicación forzada de las comunidades afectadas por las obras del complejo hidroeléctrico de Belo Monte, hechas insolentemente en contra de la legislación (desde la obtención fraudulenta de tal "consentimiento informado" hasta el incumplimiento de las "condicionantes" socioambientales exigidas para la obtención de la Licencia de Operación de la planta hidroeléctrica)-. ${ }^{15}$

2. Un aspecto fundamental de la relación entre los descendientes (biológicos y/o espirituales) de los invasores europeos de las Américas, sus aparatos político-administrativos y sus doctrinas de la nacionalidad -elaboradas con dificultad, desde el punto de vista ideológico, tanto contra las metrópolis coloniales como contra las poblaciones autóctonas- era, y de varias maneras continúa siendo, la convicción (y la implementación de la convicción) de que la condición indígena es una condición destinada a la desaparición. Los indios son vistos como representantes de un Estado sociopolítico y cultural arcaico y transitorio, que va a (deberá) extinguirse

${ }^{14}$ Nada más elocuente o revelador que el nombre de ese servicio, después reducido apenas a SPI.

${ }^{15}$ N. de T. Para un panorama de la Historia Indígena en Brasil, véase Manuela Carneiro da Cunha ed., História dos Índios no Brasil (São Paulo: Companhia das Letras, 1992). 
de un modo o de otro, para bien o para mal. ${ }^{16}$ La doctrina de la integración y asimilación de los "indios o silvícolas" a la "sociedad nacional" circuló sin impugnación hasta la Ley 6.001 de 19/12/1973, El Estatuto del Indio —que continúa en vigor, dado que el artículo 231 de la Constitución Federal Brasileña aún no ha sido reglamentado, por fuerza de los poderosos intereses que se aprovechan de las contradicciones entre esta ley y el artículo 231, el cual la invalida de modo cabal, tanto filosófica como jurídicamente, en puntos esenciales-.

3. El Estatuto de Indio tenía como eje una subcategorización de los "silvícolas" en "aislados", en "contacto intermitente", "contacto permanente" e "integrados". Esta ley dejaba en blanco su último y verdadero deseo, la subcategoría final - el indio "asimilado", el indio extinto como indio y convertido en "brasileño": caboclo, ribereño, cauchero, campesino-. En suma, el indio convertido en pobre. La categorización del Estatuto, heredera de siglos de colonialismo y de décadas de positivismo evolucionista, suponía un proceso evolutivo, en el doble sentido de una trayectoria unilineal e irreversible, por un lado, y de mejoramiento socio-moral incontestable, por el otro lado. El objetivo apenas aparentemente paradójico de las políticas de Estado era el de proteger a los indios y al mismo tiempo desindianizarlos progresivamente, sea de un modo proactivo o apenas "asistiéndolos" paternalmente en su desindianización espontánea, la cual sería un efecto natural de su contacto con una civilización superior.

4. A partir de 1975, el Ministro del Interior del gobierno de Ernesto Geisel (1975-1979), Rangel Reis, inició la elaboración de un proyecto que crearía la figura de la "emancipación de los indios", como una manera de dar una solución final al problema del desacato a lo establecido en el Estatuto del Indio de 1973, a saber, que las tierras indígenas deberían ser demarcadas

${ }^{16}$ Compárese la ética "morir si fuese preciso; matar, nunca" del indigenismo nacional-positivista de Rondon al estado en que ese "indigenismo" fue encontrado por el Procurador Jader de Figueiredo Correia (el célebre y terrible, y desaparecido por décadas, "Informe Figueiredo") [Informe de 1968 que registra la sistemática violación de derechos humanos sufrida por las poblaciones indígenas de Brasil], uno de los elementos que llevó a la extinción del SPI y a la creación de la Fundación Nacional del Indio (FUNAI) en 1967, en plena dictadura empresarial-militar. N. de T. Cândido Mariano da Silva Rondon (1965-1958) militar y explorador quien sería el primer director de la Oficina Brasileña de Protección del Indio y trabajó en la creación del Parque Nacional de Xingú. 
en el plazo de cinco años. El "proyecto de emancipación" preveía la extinción de la condición de indígena (tutelado por la Unión [del Estado brasileño] y con derecho al usufructo exclusivo de las tierras que ocupaban tradicionalmente) para aquellas comunidades que ya se encontraban "integradas". Rangel Reis expresaba sin limitaciones la opinión de que la política indigenista del gobierno debería pautarse por la directriz de la "integración rápida" de los indígenas y su consecuente emancipación. ${ }^{17} \mathrm{El}$ objetivo evidente era la liberación de las tierras de la Unión, ocupadas por los indios, para que pudieran ser incorporadas al mercado (lati)fundario capitalista. Estábamos entonces todavía en los primeros años del proceso de ocupación inducida (subsidiada y coordinada por los poderes públicos) y de la devastación acelerada de la Amazonia, proceso al cual el presente gobierno vino a dar un impulso tan gigantesco cuanto inesperado, considerándose las supuestas diferencias político-ideológicas entre la dictadura empresarial-militar y nuestro actual gobierno "democrático y popular", generosamente sustentado, como es de conocimiento general, por las mismas fuerzas económicas de los "años del plomo". ${ }^{18}$

5. Los años finales de la dictadura militar conocieron varios desdoblamientos y vaivenes de este proyecto explícitamente etnocida, de entre los cuales brilló, por así decir, una grotesca propuesta del establecimiento de "criterios de indianidad" (que incluían atributos fenotípicos, inventarios de la cultura material, etcétera), ferozmente ridiculizados por la comunidad antropológica. Debido a la reacción unánime de la sociedad civil movilizada y a la oposición interna por parte de funcionarios del órgano indigenista -oposición no siempre motivada por el noble espíritu rondoniano ${ }^{19}$ que no desapareció completamente del indigenismo de Estado-, a finales de 1978 el proyecto Rangel Reis fue "estratégicamente olvidado por algún tiempo" por la presidencia de la república. ${ }^{20}$ Estratégicamente. Por algún tiempo.

17 "Vamos a procurar cumplir las metas fijadas por el presidente Greisel, para que a través de un trabajo concentrado entre varios ministerios, de aquí a diez años podamos reducir a 20000 los 220000 indios existentes en Brasil y que de aquí a 30 años estén debidamente integrados en la sociedad nacional", en Commissão Pro-Indio, Cuadernos da Comissão Pró-Índio No. 1 (Brasil: Global Editora, 1979).

${ }^{18}$ N. de T. "Años de plomo" es la designación del periodo más represivo de la dictadura militar de Brasil, inició en 1968 y terminó en marzo de 1974.

${ }^{19}$ N. de T. Referencia a Cândido Mariano da Silva Rondon, véase la nota 17.

${ }^{20}$ Commissão Pro-Indio, Cuadernos da Comissão Pró-Índio No. 1. 
6. Vemos hoy que las acciones anti-indígenas no necesitan ser, y tal vez sea mejor que no sean, consagradas tan desvergonzadamente en instrumentos legales. Incluso, la ofensiva legislativa actual contra los derechos indígenas (PEC 215, etcétera) ${ }^{21}$ es menos explícitamente etnocida, aunque los efectos perseguidos no se distingan mucho de los del proyecto de Rangel Reis. Pero el hecho es que el Proyecto de Emancipación de la dictadura generó espectacularmente un fracaso rotundo, produciendo un resultado exactamente inverso al buscado. Pues éste fue el detonante que desencadenó una reacción pro-indígena y, más importante, una reacción indígena, cuya actividad política firme y concentrada no sólo influyó decisivamente en el contenido del capítulo "De los Indios" de la Constitución Federal de 1988, sino que transformó a los pueblos indígenas y a sus portavoces más evidentes, en actores políticos - para sorpresa e indignación de los dueños del poder- de gran visibilidad en la escena nacional e internacional. Resumamos en pocas (si es posible) palabras como sucedió esto. (Retomo en la sección siguiente, con algunas modificaciones, partes de la entrevista que concedí en 2005 al Instituto Socioambiental, con el título provocador de "En Brasil todo mundo es indio, excepto quien no es". $)^{22}$

\section{VII}

1. El Proyecto de Emancipación de la dictadura consistía en la creación de un instrumento jurídico para discriminar quien era indio de quien no era indio. El propósito era retirar de la responsabilidad tutelar (la figura de la "tutela" era incorporada en el Estatuto del Indio) del Estado a los indios que se habrían convertido en no-indios, los indios que no eran más indios,

${ }^{21}$ N. de T. PEC 215 es una enmienda constitucional propuesta a la constitución de Brasil. Pretende delegar exclusivamente al congreso el deber de demarcación de los territorios indígenas y quilombolas, así como la ratificación de las tierras ya aprobadas. Prohibiría la expansión de áreas indígenas ya existentes. Una de las secciones de la propuesta proporciona una compensación de la Unión a los agricultores que tienen propiedades absorbidas por áreas demarcadas como tierras indígenas. La Constitución federal considera que las tierras indígenas pertenecen a la Unión y, por lo tanto, no hay compensación para quienes pierden la propiedad del territorio cuando se reconoce la demarcación.

${ }^{22}$ Povos Indigenas no Brasil, "No Brasil, todo mundo é índio, exceto quem não é”, acceso el 19 de mayo de 2020, http://pib.socioambiental.org/files/file/PIB_institucional/No_ Brasil_todo_mundo_é_\%C3\% ADndio.pdf. 
esto es, aquellos individuos indígenas que "ya" no presentaban "más" los estigmas de la indianidad considerados necesarios para el reconocimiento de su régimen especial de ciudadanía (el respeto a ese régimen, bien entendido, era y es otra cosa - véase el "Informe Figueiredo"-).

2. Fue en reacción a ese proyecto de desindianización jurídica que aparecieron las Comisiones Pro-Indio y las ANAIs (Asociación Nacional de Acción Indigenista); fue también en ese contexto que se formaron o consolidaron organizaciones como el Centro de Trabajo Indigenista (Сті) y el PIB o "Proyecto Pueblos Indígenas de Brasil" del Centro Ecuménico de Documentación e Información (CEDI) (proyecto que dio origen al Instituto Socioambiental). Todo eso surgió de ese movimiento, que se constituyó precisamente en torno a la cuestión de quién es indio - no para responder a esa cuestión, sino para responder contra esa cuestión, pues ésta no era una cuestión, sino una respuesta, una respuesta que cabía "cuestionar", o sea, rechazar, dislocar y subvertir- " ¿Quién va a responder esa respuesta?", pregunta el personaje del documental de Werner Herzog. Justamente: cómo responder a la respuesta que el Estado tomaba como incuestionable en su cuestión, a saber: que "indio" era un atributo determinable por inspección y mencionable por ostentación, una substancia dotada de propiedades características, algo que se podría decir qué es, y quién cumple los requisitos de tal cualidad - ¿cómo responder a esa respuesta?-- Pues, al creer en ella, se trataría solamente de mandar llamar a los peritos y pedirles que indicasen quién era y quién no era indio.

3. Nótese que, en aquella época, la cuestión de saber quién era indio no se cristalizaba en torno de aquello que llegó a llamarse etnias emergentes, fenómeno bastante posterior: fueron tales nuevas etnicidades, al contrario, que surgieron de la cuestión, respondiendo a ella con una respuesta genial, esto es, inesperada. El problema de la época, muy al contrario de cualquier "emergencia”, era el problema de las etnias submergentes, de aquellos colectivos que estaban siguiendo, por fuerza de las circunstancias de etnocidio generalizado, una trayectoria histórica de alejamiento de sus referencias indígenas y de los cuales, con ese pretexto, el gobierno quería librase: "Esa gente ya no es india, nos lavamos las manos. No tenemos nada que ver con eso. Que se liberen sus tierras para el agronegocio y el desarrollo nacional; que se les deje su fuerza de trabajo en el mercado". 
4. Nuestro objetivo político y teórico, como antropólogos, era establecer definitivamente que indio no es una cuestión de penacho de pluma, achiote para pintarse el cuerpo y arco-y-flecha, algo aparente y evidente en ese sentido estéreotipificante, sino una cuestión de "estado de espíritu". Un modo de ser y no un modo de parecer. La verdad, algo más (o menos) que un modo de ser: la condición indígena designaba para nosotros un cierto modo de devenir (véase la sección v, supra), algo esencialmente "invisible", aunque no por eso menos eficaz: un movimiento incesante de diferenciación, no un estado masivo de "diferencia" previa y estabilizada, esto es, una "identidad”. Nuestra lucha, por tanto, era conceptual: nuestro problema era hacer que el "todavía" del juicio del sentido común: "esas personas todavía son indios" (o "no es más indio") no significase un estado transitorio o una etapa a ser vencida. La idea que defendimos es aquella donde los indios "todavía” no habían sido vencidos, ni jamás lo serían. Ellos jamás acabar(í)an ${ }^{23}$ de ser indios, "todavía que...". O justamente porque. En resumen, la idea era que "indio" no podía ser entendido como una etapa en la marcha de ascensión hasta el envidiable estado "blanco" o "civilizado".

5. Mas la filosofía de la legislación brasileña era justamente ésa: todos los indios "todavía" eran indios, en el sentido en que un día irían, porque debían, dejar de serlo. Incluso los que estaban desnudos en la selva, con sus proverbiales penachos de plumas, sus collares de cuentas, sus arcos, flechas, garrotes, cerbatanas, los indios con "contacto intermitente" o los "aislados" -incluso esos todavía eran indios-. Apenas todavía; o sea, todavía, sólo, porque todavía no eran no-indios. El objetivo de la política indigenista de Estado era administrar (y, como vimos, acelerar) un movimiento visto como inexorable (y deseable): el célebre "proceso histórico", artículo de fe, común a los más variados credos modernizadores, del positivismo al marxismo. Todo lo que se "podía hacer" era garantizar — eso para los más bien-intencionados- que el "proceso" no fuese demasiado brutal. Pero, de una forma o de otra, se entendía que el anhelado mestizaje nacional sólo podría ser hecho, bien, se sabe cómo: destrozando las identidades indígenas, disolviendo las diferencias étnico-culturales, subyugando políticamente a los pueblos indígenas que todavía mantenían su autonomía. Etnocidio, un crimen piadoso.

${ }^{23}$ N. de T. En el original, juego de palabras entre el hecho de acabaram, literalmente acabaron, y la posibilidad de acabariam. 
6. La lucha contra el proyecto de emancipación llevó a las personas y a los movimientos sociales que estaban del lado de los indios a preocuparse por los censos, los registros, con información, con organización, comunicación y propaganda. Se trataba, en suma, de visibilizar la cuestión. No dejó de ser una suerte que los generales y coroneles de la época intentaran desindianizar por ley las comunidades indígenas, pues eso, la verdad, terminó por reindianizarlas. La desordenada tentativa de la dictadura de legislar sobre la ontología de la indianidad "desinvisibilizó" a los indios, que eran virtualmente inexistentes como actores políticos en las décadas de 1960 y 1970. Ellos sólo aparecían, de vez en cuando, en algún reportaje colorido sobre el Xingú, generalmente como ilustración del admirable trabajo de los hermanos Villas Bõas. ${ }^{24}$ El escándalo suscitado con el proyecto de emancipación rescató la cuestión indígena del folclor residual de masa a la que había sido reducida. Dicho proyecto generó que los indios se dieran cuenta de que, si ellos no tenían cuidado, iban a dejar de ser indios, y de prisa. Gracias a eso, entonces y al fin, los indios se volvieron mucho más visibles como actores y agentes políticos en el escenario nacional e internacional. Los primeros líderes indígenas de expresión supralocal surgieron en ese contexto, como Mário Juruna, Raoni, Marçal Tapã, Angelo Kretã, Álvaro Tukano e Aílton Krenak.

7. Hasta aquel momento, muchos colectivos indígenas sentían vergüenza de serlo, y el gobierno tenía todo el interés en aprovechar esa vergüenza inculcada sistemáticamente, extrayendo las consecuencias jurídico-políticas del eclipsamiento histórico de la cara indígena de varias comunidades de caboclos, sertanejas, ${ }^{25}$ ribereñas, caiçaras,${ }^{26}$ caipiras ${ }^{27}$ del país. En los viejos

${ }^{24}$ N. de T. Los Hermanos Villas-Bôas, Orlando (1914-2002), Cláudio (1916-1998) y Leonardo Villas-Bôas (1918-1961), fueron importantes sertanistas brasileños y activistas de los derechos de los indígenas. Lanzaron una campaña en todo el país que condujo a la creación del Parque nacional Xingú en 1961, una reserva de 25000 kilómetros cuadrados situada en el estado de Mato Grosso. Trasladaron a varios grupos indígenas a este territorio relativamente seguro.

${ }^{25}$ N. de T. Habitantes de la región centro-sur de Brasil.

${ }^{26} \mathrm{~N}$. de T. Habitantes del litoral de las regiones sur y sureste de Brasil.

${ }^{27}$ N. de T. El término caipira, que en tupí significa "cortador de montes", es el nombre que los indígenas del interior del estado de San Paulo le dieron a los hombres blancos y caboclos. Es, por extensión, una designación genérica dada a los habitantes del interior del Estado de San Paulo, que comprende la totalidad del estado menos la Región Metropolitana de San Paulo y el litoral paulista. 
tiempos de la antigua izquierda nacional-popular, los especialistas en el "proceso histórico" nos martillaban los oídos con el dogma de que la "condición campesina" (como opción de "proletarización") era el devenir histórico inexorable y por tanto la verdad de las sociedades indígenas, y que la descripción de esas sociedades como entidades socioculturales auto-referidas - como minorías étnicas indígenas, entiéndase- suponía un "modelo naturalizado" y "a-histórico" de la dinámica histórica de Brasil. Pero aquí que, poco a poco, los indios comenzaron a reivindicar y terminaron por obtener el reconocimiento constitucional de un estatuto diferenciado permanente dentro de la llamada "comunión nacional"; aquí ellos comenzaron a implementar ambiciosos proyectos de retradicionalización, marcados por un autonomismo "culturalista" que, por instrumentalista y etnicizante, no es menos primordialista ni menos naturalizante; aquí, finalmente, algunas comunidades rurales situadas en las áreas arquetípicamente "campesinas" del país reasumieron su condición indígena, en un proceso de transfiguración étnica que es el exacto inverso de aquél anunciado, en los idus de 1970, por Darcy Ribeiro en el célebre Os índios e a civilización, cuya profecía fue seguida, con un retoque u otro, por la mayoría de los antropólogos.

8. Con la Constitución de 1988, el juego cambió completamente. De hecho, hubo una inversión de 180 grados en relación con el proyecto de emancipación. El propósito explícito de ese proyecto era emancipar individuos, pero su verdadero objetivo, como se sabe, era el de "liberar" comunidades enteras. Con la Constitución, se consagró el principio de que las comunidades indígenas se constituyesen en sujetos colectivos de derechos colectivos. El "indio" dio lugar a la "comunidad" (un día vamos a llegar al "pueblo" - quién sabe-), y así lo individual cedió el paso a lo relacional y a lo transindividual, lo que fue, innecesario enfatizar, un paso gigantesco, incluso si ese transindividual necesitó asumir la máscara del supra-individual para figurar en la metafísica constitucional, la máscara de la Comunidad como Súper-Individuo. Pero de cualquier modo lo individual no podría dejar de ceder a lo relacional, una vez que la referencia indígena no es un atributo individual, sino un movimiento colectivo, y que la "identidad indígena" no es "relacional" sino apenas "en contraste" con identidades no-indígenas, pero relacional (luego, no es exactamente una "identidad"), ante todo, porque constituyen colectivos transindividuales 
intrarreferenciados e intradiferenciados. Hay individuos indígenas porque ellos son miembros de comunidades indígenas, y no lo inverso.

9. Fue a partir de ese momento que se aceleró la "emergencia" de las comunidades indígenas que estuvieron sumergidas por varias razones: porque fueron enseñadas a no decir más que eran indígenas, o enseñadas a decir que no eran más indígenas; porque las metieron en una licuadora políticoreligiosa, un moledor cultural que mezcló etnias, lenguas, pueblos, regiones y religiones, para producir una masa homogénea capaz de servir de "población”, esto es, de sujeto (en el sentido de súbdito) del Estado. Como se sabe, las antiguas misiones, el origen de tantas ciudades, villas, pueblos y campamentos del interior de Brasil, fueron los lugares privilegiados de esa fabricación del componente indígena del "pueblo brasileño", al sintetizar los célebres indios genéricos, los indios reducidos en aldeas, catecúmenos del sacramento estatal de la transustanciación étnica: la comunión nacional... La Constitución de 1988 interrumpió jurídicamente (ideológicamente) el proyecto multisecular de desindianización, al reconocer que éste no se había completado y al sancionar el derecho permanente a la condición indígena. Y fue así que las comunidades en proceso de distanciamiento de la referencia indígena comenzaron a percibir que volver a "ser" indio - volver a convertirse en indio, retomar el proceso incesante de convertirse en indio-podía ser interesante. Convertir, revertir, pervertir o subvertir el dispositivo de sujeción armado desde la Conquista para convertirlo en dispositivo de subjetivación; dejar de sufrir la propia indianidad y comenzar a gozarla. Una gigantesca abreacción colectiva, para usar viejos términos psicoanalíticos. El retorno del reprimido nacional.

\section{$\mathrm{X}$}

1. El Capítulo "De los indios" de la Constitución Federal de 1988 define con claridad los derechos de los indios, en particular los derechos colectivos de las comunidades indígenas; como ya observamos, esa definición permite caracterizar como etnocidio cualquier iniciativa o acción, del gobierno o de particulares, que viole tales derechos. Entretanto, y por motivos ciertamente deliberados, la Constitución no define quién es el sujeto de esos derechos, o en otras palabras quién es indio en Brasil y qué es una comunidad indígena. 
$3{ }^{28}$ Los investigadores de la Universidade Federal de Minas Gerais (UFMG) que realizaron un estudio sobre el aporte genético amerindio en la población nacional descubrieron que éste es mucho mayor de lo que imaginaban. Algo como 33\%, creo. Al final de cuentas, entonces, el flujo genético amerindio continúa con la rienda suelta. Interesante, pero eso no tiene la menor importancia, excepto por lo que puede ayudar a aclarar sobre la historia "de Brasil" - sobre el uso y abuso sexual de las mujeres indias (y esclavas) por los señores blancos, por ejemplo-. Los colectivos caiçaras, caboclos, campesinos e indios son indios (y no 33\% indios) en el sentido de que son el producto de una historia, una historia que es la historia de un trabajo sistemático de destrucción cultural, de sujeción política, de "exclusión social" (o peor, de "inclusión social"), trabajo ese que es propiamente interminable. No fue posible lograr que todos los brasileños dejaran de ser indios completamente. Por más exitoso que haya sido o esté siendo el proceso de desindianización llevado a cabo por la catequización, por la misionerización, por la modernización, por la ciudadanización, no es posible reducir la historia a cero y suprimir toda la memoria, porque los colectivos humanos existen crucial y eminentemente en el momento de su reproducción, en la transición intergeneracional de aquel modo relacional que "es" el colectivo, y, a menos que esas comunidades sean físicamente exterminadas, expatriadas, deportadas, es muy difícil destruirlas completamente. Raros son los genocidios totales y difíciles los etnocidios perfectos. Y todavía cuando el trabajo fue llevado al extremo, cuando las colectividades indígenas y afro descendientes fueron reducidas a sus componentes individuales, extraídos de las relaciones que los constituían, como sucedió paradigmáticamente con los esclavos africanos, esos componentes reinventaron una cultura y un modo de vida - un mundo relacional que, por limitado que haya sido por las condiciones adversas donde floreció, jamás dejó de ser una expresión de la vida humana exactamente como cualquier otra-. No hay culturas inauténticas, pues no hay culturas auténticas. No hay, además, indios auténticos. Indios, blancos, afrodescendientes o quien quiera que sea - pues "auténtico" no es una cosa que los humanos sean-. O tal vez sea una cosa que sólo la Mayoría, los "blancos" como Mayoría, puede ser (peor para ellos). La autenticidad es una auténtica invención de la metafísica occidental o incluso más que eso -ella es

\footnotetext{
${ }^{28}$ N. de T. En el original pasa del uno al tres.
} 
su fundamento, entiéndase, es el concepto mismo de fundamento, concepto arquimetafísico-. Sólo el fundamento es completamente auténtico; sólo lo auténtico puede ser completamente fundamento. Pues lo Auténtico es el avatar del Ser, una de las máscaras utilizadas por el Ser en el ejercicio de sus funciones monárquicas dentro de la onto-teo-antropología de los blancos. ¿Qué diablos tendrían los indios que ver con esto?

4. Aunque el concepto antropológico de minoría étnica indígena sea de difícil traducción en el vocabulario y en el imaginario del orden jurídico del Estado-nación, no es imposible proponer una definición tentativa, provisional, de la condición indígena que pueda ser aprovechada por el legislador. Antes de exponerla, sin embargo, conviene comenzar por una cautela fundamental. Los enunciados - las reivindicaciones con intención de reconocimiento de derechos-de indianidad son enunciados performa$\operatorname{tivos}^{29}$ y no enunciados verificables, por tanto, dependen de "condiciones de felicidad" y no de "condiciones de verdad" (en el sentido de correspondencia con un estado de cosas). Pero, y éste es el punto crucial, las condiciones antropológicas de felicidad de tal enunciado no son dadas por terceros. Sobre todo, no son ni pueden ser dadas por el Estado, el Tercero por excelencia. La indianidad es tautegórica; ella crea su propia referencia. Indios son aquellos que se "representan a sí mismos", en el sentido que Roy Wagner otorga a esta expresión (véase The Invention of the Culture, 1981), sentido que no tiene nada que ver con la "identidad"; y nada que ver, tampoco, con la "representación”, como está indicado en la formulación deliberadamente paradójica de la expresión. "Representarse a sí mismo" es aquello que hace una Singularidad, y lo que una Singularidad hace. Por más abstrusas que esas consideraciones puedan parecer, ellas simplemente explicitan los principios de autodeclaración y de autodeterminación definidos en la Resolución de las Naciones Unidas sobre los Derechos de los Pueblos Indígenas. Pero pasemos a la tentativa de la definición de sujeto del capítulo vir de la Constitución Federal Brasileña.

${ }^{29}$ En el sentido establecido por el filósofo John Austin en su célebre libro dado a la luz en 1962. John Langshaw Austin, How to Do Things with Words (Massachusetts: Harvard University Press, 1962). Edición en español: John Langshaw Austin, Cómo hacer cosas con palabras. Palabras y acciones (España: Paidós Ibérica, 1981). 
5. ¿Quién es indio en Brasil?

5.1. "Indio" es cualquier miembro de una comunidad indígena, reconocido por ella como tal.

5.2. "Comunidad indígena" es toda comunidad fundada en relaciones de parentesco o vecindad entre sus miembros, mismos que mantienen lazos histórico-culturales con las organizaciones indígenas precolombinas.

5.2.1. Las relaciones de parentesco o vecindad constitutivas de la comunidad incluyen las relaciones de afinidad, de filiación adoptiva, de parentesco ritual o religioso, y, más generalmente, se definen en términos de la concepción de los vínculos interpersonales que son fundamentalmente propios para la comunidad en cuestión.

5.2.2. Los lazos histórico-culturales con las organizaciones precolombinas incluyen dimensiones históricas, culturales y sociopolíticas, a saber:

a) La continuidad de la presente implantación territorial de la comunidad en relación con la situación existente en el periodo precolombino. Tal continuidad no excluye la derivación de la situación territorial presente a partir de las contingencias impuestas por los poderes coloniales o nacionales del pasado, tales como migraciones forzadas, eliminaciones, reducciones, congregación en aldeas y demás medidas de asimilación u oclusión étnicas;

b) La orientación positiva y activa del grupo ante discursos y prácticas comunitarias derivadas del fondo cultural amerindio y concebidas como patrimonio relevante del grupo. En vista de los procesos de destrucción, reducción y oclusión cultural asociados a la situación evocada en el ítem anterior, tales discursos y prácticas no son necesariamente aquéllos específicos del área cultural (en el sentido histórico-etnológico) donde se encuentra hoy la comunidad;

c) La decisión, sea manifiesta o simplemente asumida, de la comunidad para construirse como entidad socialmente diferenciada dentro de la comunión nacional, con autonomía para establecer y deliberar su composición (modos de reclutamiento y criterios de inclusión de sus miembros) y asuntos internos (gobernanza comunitaria, formas de ocupación del territorio, régimen de intercambio con la sociedad circundante), así como para definir sus modalidades propias de reproducción simbólica y material. 


\section{$\mathrm{XI}$}

1. Comentemos este ejercicio. El punto realmente fundamental para elegir a la "comunidad" como sujeto de la definición es que el sustantivo o adjetivo "indio" no designa o califica a un individuo, sino que especifica un cierto tipo de colectividad. En este sentido no existen indios, sino solamente comunidades, redes de/y relaciones que se pueden llamar indígenas. No hay cómo determinar quién "es indio", independientemente del trabajo de auto-determinación realizado por las comunidades indígenas, aquellas que son el objeto del presente ejercicio definicional.

2. "Comunidad indígena es toda comunidad fundada en relaciones de parentesco o vecindad entre sus miembros" (5.1). El "o" aquí es inclusivo: "sea parentesco, sea vecindad". Ése es un punto importante, porque impide una definición genética o meramente genealógica de la comunidad. La idea de vecindad sirve para subrayar que "comunidad" no es una realidad genética; por otro lado, incluir "relaciones de parentesco" en la definición permite que se contemplen posibles dimensiones translocales de esa "comunidad". En otras palabras, la comunidad aquí prevista es o puede ser una realidad tanto temporal como espacial. En suma, "parentesco" y "territorio" son entendidos como principios alternativos o conjuntivos de constitución de una comunidad. Conviene subrayar el carácter no-geométrico de ese territorio: la inscripción espacial de la comunidad no necesita ser, por ejemplo, concentrada o continua, pudiendo al contrario ser dispersa y discontinua.

3. Comentemos la primera especificación (5.2.1): "Las relaciones de parentesco o vecindad constitutivas de la comunidad incluyen las relaciones de afinidad, de filiación adoptiva, de parentesco ritual o religioso (por ejemplo compadrazgo), y, más generalmente, se definen en los términos de la concepción de los vínculos interpersonales fundamentalmente propios de la comunidad en cuestión". Dicho claramente, es pariente quien los indios consideran como su pariente y no quien en un laboratorio oficial decida, a partir de un examen de sangre o de ADN. Parentesco incluye la afinidad. Esto es básico, en primer lugar, porque las relaciones de afinidad son, en muchas culturas indígenas, transmisibles intergeneracionalmente, exactamente como las relaciones de consanguinidad; en segundo lugar porque, de un modo general, la antropología ha mostrado que la afinidad es el marco político y el lenguaje ideológico dominante en las comunidades amerindias. Y, 
finalmente, porque hay muchos casamientos interétnicos en los mundos indígenas de hoy. Así, las relaciones de parentesco y de vecindad incluyen lazos variados y, sobre todo, se definen en términos de la actualización de los vínculos interpersonales fundamentalmente propios de la comunidad en cuestión. La comensalidad, la vecindad pueden prevalecer sobre ideas relativas a la "sangre". Cada comunidad tendría una concepción específica de lo que son esos "vínculos interpersonales fundamentales", y esas concepciones deben ser en "definitiva" de las comunidades, no las nuestras.

4. Los "lazos histórico-culturales con las organizaciones sociales precolombinas" (5.2.2) son evidentemente importantes, pues es veleidad imaginar que se pueda definir "indio" sobre la base del principio falaz pseudo-relativista según el cual "indio es cualquiera que pretende serlo". No es cualquiera; y no basta con pretender o decir; la autodeclaración requiere de la presentación de razones históricas y etnohistóricas para tal acto. Es necesario sumar en esta definición, por tanto, el reconocimiento explícito del hecho que existe un mundo social precolombino y de que hay una cantidad de comunidades y colectivos en el Brasil actual que se sienten vinculadas con él. Lo que quiere decir que ese "vínculo" es el problema, naturalmente. Los lazos histórico-culturales con las organizaciones sociales precolombinas incluyen dimensiones históricas, culturales y sociopolíticas. No es necesario tener una coincidencia de esas tres dimensiones. Esas condiciones dimensionales son condiciones suficientes, cada una por sí misma. Y ninguna de ellas es necesaria. ¿Cuáles son tales condiciones? Una de ellas es la continuidad de la implantación territorial de la comunidad en relación con la situación existente en el periodo precolombino. Es la idea de territorio tradicional, de la Tierra inmemorial. Lo que distingue a las minorías étnicas indígenas es precisamente su condición indígena, en el sentido etimológico. ${ }^{30}$ Es imposible no reconocer la importancia de esto. Como indicamos, sin embargo, tal continuidad es suficiente, pero no es necesaria. Pues no menos suficiente es la disposición para entender la situación presente de la comunidad a partir de las violencias impuestas por los poderes coloniales o nacionales: eliminaciones, reducciones, congregaciones en aldeas y demás medidas propiamente etnocidas. La

${ }^{30}$ Indígena-ETim. Lat. Indígena, $x$, "natural del lugar en que vive, generado de la tierra que le es propia...' (Diccionario Houaiss da Língua Portuguesa, s.v. El subrayado es mío). Esa "propiedad", me permito interpretar, es atributo inmanente del sujeto, no una relación extrínseca con un objeto apropiable. No son pocos los pueblos indígenas del mundo que afirman que la tierra no les pertenece, pues son ellos que pertenecen a la tierra. 
persistencia de la memoria del origen es la única fecha de caducidad en estos casos. Y la memoria, como se sabe, tiene sus usos sociales.

5. El otro aspecto definicional (5.2.2/b) es la orientación positiva y activa de los miembros del grupo frente a discursos y prácticas comunitarias derivados del fondo cultural amerindio y concebidos como patrimonio colectivo relevante. Si tomamos la cuestión por la otra punta, eso quiere decir: ninguno está obligado a ser indio. Los miembros de una comunidad pueden decidir: "nosotros tal vez seamos indios, pero no queremos serlo; de cualquier manera, estamos convirtiéndonos en blancos". La noción de "convertirse en blanco", como se sabe, está presente en varios mundos indígenas. Ésta no implica necesariamente lo que nosotros suponemos que quiere decir; al contrario, lo que ella quiere decir es justamente uno de los problemas más complejos con los que se enfrentan los antropólogos. Algunos blancos lamentan que hay varios blancos queriendo convertirse en indios y, al mismo tiempo, hay otros blancos que lamentan que hay varios indios queriendo convertirse en blancos. Los yanomami quieren convertirse en blancos y algunos caboclos allá en el sertón de Cariri quieren convertirse en indios. El mundo está de cabeza para abajo. Los yanomami deberían seguir queriendo ser indios (alguien necesita seguir queriendo serlo; algunos indios son necesarios) y los caboclos deberían seguir queriendo ser blancos, cada vez más blancos - la ciudadanía-. La verdad, esas dos cosas son mucho más complicadas de lo que se imagina. Aquellos (pocos) yanomami que dicen estar "convirtiéndose en blancos", no están diciendo exactamente lo que se imagina que están haciendo, y los caboclos del sertón nordestino que "quieren" convertirse en indios (o "pasar para indígena", como se dice en varias comunidades ribereñas de la Amazonia), tienen sus propias ideas sobre lo que eso significa. Cabe a los antropólogos discernir y diferenciar toda la complejidad que hay detrás de aseveraciones tan banales como "nosotros nos estamos convirtiendo en blancos". Ése es un discurso común, como decimos, en algunas comunidades indígenas: "nosotros nos estamos convirtiendo en blancos", "los indios están acabándose". Lo que parece, sin embargo, es que nunca se acaba de convertirse en blanco; y que los indios no terminan de terminarse; es necesario seguir siendo indio para poder seguir convirtiéndose en blanco. Y parece también que convertirse en blanco a la manera de los indios no es exactamente la misma cosa que convertirse en indio a la manera de los blancos. Hasta que se convierta. Pero ahí, como se sabe, aquello que se convirtió se convirtió en otra cosa. 
6. Continuando el comentario del ítem 5.2.2/b: "debe" de haber una orientación positiva y activa del grupo en relación con los productos característicos de la vida comunitaria. Rituales, mitos, configuraciones relacionales más o menos reificadas, la propia comunidad en cuanto punto de orientación, polo de la territorialización, y así sucesivamente. En vista de los procesos de desmigajamiento antropológico asociados con la situación ya evocada (reducciones, eliminaciones, esclavización, catequización, etcétera), tales discursos y prácticas no son específicos del "área cultural”, en el sentido histórico-etnológico, donde hoy se encuentra la comunidad. O sea, ciertos indios pueden tener una orientación positiva y activa en relación con el fondo cultural amerindio, pero un fondo que remite a otra región "original”, simplemente porque la de ellos fue destrozada. Entonces, si los caboclos del Nordeste importan un chamán wajãpi para enseñar el ritual de toré ${ }^{31}$ hoy un signo diacrítico de la indianidad nordestina, ¿̇cuál es el problema? Los antiguos romanos importaban profesores de griego para enseñarles filosofía griega y nadie decía que por eso los romanos estaban dejando de ser romanos. O decían (algunos romanos de hecho decían), pero ni por eso dejaron de ser romanos.

7. La tercera dimensión (5.2.2/c), al final, es la sociopolítica - la primera era histórica (continuidad), la segunda, cultural (orientación positiva en relación con el fondo cultural)—. La dimensión sociopolítica se refiere a la decisión, manifestada o simplemente asumida, de que la comunidad se construye como un cuerpo socialmente diferenciado dentro de la comunión nacional - para usar ese lenguaje ligeramente hipócrita-. Se construye como entidad socialmente diferenciada significa otorgarse autonomía para establecer y deliberar sobre su composición, esto es, los modos de reclutamiento y los criterios de exclusión de la comunidad. Estamos hablando de cosas como "gobernanza" comunitaria, modalidades de ocupación del territorio, regímenes de intercambio con la sociedad circundante, dispositivos de reproducción material y simbólica... Los indios tienen, como dice la Constitución, derecho a sus usos y costumbres y tradiciones. Tener derecho a los usos y costumbres significa tener autonomía para gobernarse internamente

${ }^{31}$ N. de T. El toré, danza y canto ritual, es uno de los íconos de la indianidad nordestina y codifica la autoctonía de los indios de la región del Nordeste de Brasil. A partir de la mitad del siglo xx, el toré es una forma de expresión política incorporada en el movimiento indígena. 
"en aquello que no hiera los principios fundamentales" (como si nosotros no los hiriéramos, por principio) de la constitución nacional.

\section{Conclusión}

1. En este momento, en esta república, en este gobierno, presenciamos una maquinación política concertada que tiene como objetivo las áreas de preservación ambiental, las comunidades quilombolas, las reservas extractivistas y en especial los territorios indígenas. Su objetivo es consumar la "liberación" (la desprotección jurídica) del mayor número posible de tierras públicas o, más en general, de todos aquellos espacios bajo regímenes tradicionales o populares de territorialización que se mantienen fuera del circuito inmediato del mercado capitalista y de la lógica de la propiedad privada, con el fin de volver "productivas" esas tierras, esto es, lucrativas para quienes las pretenden, los grandes empresarios del agronegocio, de la minería y de la especulación latifundista, varios de ellos reunidos en los curules del Congreso, muchos apenas pagando sus títeres para "operar" en ese lugar. La verdad, son los Tres Poderes de nuestra república federativa que han tejido una ofensiva criminal en contra de los derechos indígenas, ${ }^{32}$ conquistados a duras penas entre 1978, año del "Proyecto de emancipación" de la dictadura, y 1988, año de la "Constitución ciudadana” que reconoció los derechos originarios de los pueblos indígenas sobre sus tierras, consagrando y perennizando el instituto fundamental del indigenato. Esa recepción de los indios como una categoría sociocultural diferenciada de pleno y permanente derecho dentro de la nación suscitó una feroz determinación represiva por parte del sistema del latifundio, que hoy ocupa varios ministerios, controla el Congreso y posee una legión de sirvientes en la Judicatura. Llueven, de todas las instancias y niveles de los poderes constituidos, tentativas de desfigurar la Constitución que los constituyó, por medio de proyectos legislativos, decretos oficiales ejecutivos y decisiones tribunales que convergen en el propósito de extinguir el espíritu de los artículos de la Ley Mayor que garantizan los derechos indígenas.

${ }^{32}$ Véase la entrevista de Henyo Barreto y Clarissa Presotti, "Três Poderes contra os direitos indígenas", acceso el 20 de mayo de 2020, http://www.portalambiental.org.br/pa/ noticias?id=134. 
2. El presente gobierno, y me refiero aquí al Ejecutivo, desde su comandante hasta sus subordinados ministeriales, ha mostrado el peor desempeño, desde nuestra tímida redemocratización, en lo referente a estos derechos, agravando la ya pésima administración anterior sobre la misma dirección: procedimientos de demarcación y homologación de tierras indígenas prácticamente nulos; $;^{33}$ políticas de salud más que omisas, desastrosas para las comunidades indígenas; una indiferencia casi indistinguible de la complicidad ante el genocidio practicado continua y descaradamente sobre los Guaraní-Kaiowá, o periódicamente y "por descuido" sobre los yanomami y otros pueblos nativos, así como frente al asesinato metódico de líderes indígenas y ambientalistas por todo el país —cuestión en la cual Brasil es, como se sabe, campeón mundial一.

3. Véase por fin, aunque no menos lamentable, la joya de la corona de la suprema mandataria de la república, ${ }^{34}$ a saber, la construcción a destajo, por megaempresas del capital privado al servicio del poder público y/o viceversa, insolentemente en contra de la legislación y a expensas de "financiamientos" de dimensiones obscenas, hechos con el llamado dinero del pueblo, de decenas de hidroeléctricas en la cuenca amazónica, que traerán gravísimos daños a la vida de centenas de pueblos indígenas y de millares de comunidades tradicionales ${ }^{35}$ - para no hablar de las decenas de

${ }^{33}$ N. de T. De acuerdo con la Constitución de Brasil corresponde a la Unión demarcar, proteger y hacer respetar todas las propiedades de las comunidades indígenas (art. 231). Para este fin se creó la FUNAI, responsable de proteger a los pueblos indígenas y regularizar sus tierras. El procedimiento de regularización o titulación comprende los siguientes pasos: 1) estudio de identificación del área, 2) aprobación de la FUNAI, 3) reclamos, 4) delimitación (a través de un decreto se establecen los límites de la tierra indígena), 5) demarcación física, 6) homologación (el procedimiento de demarcación es sometido al presidente de la república, para su homologación por decreto), 7) registro y regularización.

${ }^{34}$ N. de T. En ese momento Dilma Rousseff.

${ }^{35}$ Llámese "poblaciones tradicionales" ("ribereñas", “caboclas”), a aquellas comunidades campesinas y extractivistas de la cuenca amazónica cuya consciencia de la relación con los pueblos indígenas que las precedieron parece haber sido, en algunos casos, abolida. La cultura traída por los migrantes "blancos" (de origen principalmente nordestino) que se fundió con el "sustrato" autóctono reprimió toda memoria nativa y se orientó miméticamente hacia el Brasil oficial. En la mayoría de los casos, por tanto, la relación permaneció latente, expresándose "vestigialmente" por automatismos prácticos e idiomatismos simbólicos. Esta aparente pérdida de consciencia, así, se ha mostrado más frecuentemente no como una ruptura definitiva, sino como un largo desmayo - un especie de coma étnico del cual la Amazonia "cabocla" comienza a despertar, como muestra el hecho de que, hoy, sólo en el Médio Salimões, cerca de doscientas comunidades tradicionales reivindican su "pasaje a lo indígena", 
millares de otras especies de habitantes de la selva, que viven en ella, de ella y con ella; que son, finalmente, la selva misma, el macrobioma o megarizoma autotrófico que cubre un tercio de América del Sur, y cuya estructura lógica-metafísica fue claramente expuesta en el libro admirable, recientemente publicado, de Davi Kopenawa y Bruce Albert, A queda do céu-. ¿Pero de que vale todo esto ante las leyes inexorables de la Economía Mundial y el objetivo supremo del Progreso de la Patria? La entropía creciente se transfigura dialécticamente en antropía triunfante. Y todavía se dice que son los indios quienes creen en cosas imposibles.

4. En suma, lo que la dictadura empresarial-militar no consiguió exterminar, la coalición comandada por el Partido de los... ¡Trabajadores! (PT) de Brasil lo ha destruido con eficiencia aterradora. Su instrumento material para ello han sido las mismas fuerzas político-económicas que apoyaron y financiaron el proyecto de poder de la dictadura. Tal "eficiencia" destructiva, nótese bien, está lejos de la "destrucción creadora" marxista y schumpeteriana, ${ }^{36}$ si esto sirve de algo para lo que queda en los sombríos tiempos que corren. No hay absolutamente nada de creador y menos todavía de creativo, en lo que la clase dominante y su órgano ejecutivo hacen en la Amazonia. Lo que falta en inteligencia y discernimiento sobra en ganancia y violencia.

5. Eliane Brum, notable periodista y escritora, una de las pocas voces en la prensa brasileña que consiguió hacerse oír a través de la cortina de silencio

esto es, su condición de titulares de los derechos reconocidos en el artículo 231 de la Constitución Federal de Brasil (Deborah Lima 2015, comunicación personal), citando datos de Rafael Barbi para los ríos Copacá, Tefñe, Uarini, Jataí, Caiambé y Mineruá; las reservas de Mamirauá y Amanã responden por 50 comunidades de este total). El fenómeno es general en el "Brasil profundo" y parece todavía más paradójico cuando se constata que se intensificará en la medida en que este Brasil profundo "salga a la superficie", esto es, modernizandose, insertándose en las redes por donde circulan los flujos semiótico-culturales que atraviesan el planeta, del dinero al internet.

${ }^{36}$ N. de T. Referencia a Joseph Alois Schumpeter (1883-1950). Economista austro-estadounidense, ministro de Finanzas en Austria y profesor de la Universidad de Harvard que destacó por sus investigaciones sobre el ciclo económico y por sus teorías sobre la importancia vital del empresario. Popularizó el concepto de destrucción creativa como forma de describir el proceso de transformación que acompaña a las innovaciones. Predijo la desintegración sociopolítica del capitalismo que, según él, se destruiría debido a su propio éxito. Véase Wikipedia, “Joseph Alois Schumpeter”, acceso el 12 de junio de 2020, https://es.wikipedia.org/wiki/Joseph_Alois_Schumpeter. 
erigida por esta misma prensa, gracias a su coraje, talento y firmeza, observaba hace algunas semanas: ${ }^{37}$

Nada es más autoritario que decir a otro que no es lo que es. Ésa también es parte de la ofensiva de aniquilación, al invocar la falaz cuestión del "indio verdadero" y del "indio falso", como si existiese una especie de "certificado de autenticidad". Esa estrategia es todavía más vil porque pretende convencer al país de que los pueblos indígenas ni siquiera tendrían el derecho de reinvindicar pertenecer a la tierra que reivindican, porque ni siquiera pertenecerían a sí mismos. En la lógica del explotador, lo ideal sería transformar a todos en pobres, moradores de las periferias de las ciudades, dependientes de programas de gobierno. En ese lugar, geográfico y simbólico, ningún privilegio estaría en riesgo. Y no habría nada entre los grandes intereses sin ninguna grandeza y el territorio que codicia.

6. En efecto, transformar al indio en pobre - la verdadera definición antropológica y política de etnocidio-, que es lo que pretende el "explotador", es también la realización objetiva de la visión del mundo del progresismo populista que se instaló en el Estado, pero que prolifera igualmente fuera de él, en nuestra izquierda de ascendencia intelectualmente blanca y europea: a saber, aquella visión que concibe lo "indio" como una subespecie del "pobre". Esa metamorfosis conceptual hace del indio el bienvenido objeto de una apresurada necesidad, la de transformarlo, paternalmente, en "no-pobre", retirándolo de su abyección y de volverlo un "ciudadano", pasar de una condición de "menos que nosotros" a la de un "igual a nosotros". La pobreza es una condición que debe ser remediada, es la diferencia injusta que debe ser abolida. Y tengan "programa de gobierno", corriendo luego tras de la cosechadora, del agrotóxico, del pivote de irrigación, de la presa -todo, naturalmente, financiado por las proezas de nuestro agrocapitalismo-. Pero un indio es distinto a un pobre. Él no quiere ser transformado en alguien "igual a nosotros". Lo que él desea es poder permanecer diferente de nosotros - justamente diferente de nosotros-. Él quiere que reconozcamos y respetemos su distancia. Una vez más, ésta es la elección crucial de nuestro país, en el presente momento histórico

${ }^{37}$ N. de T. Eliane Brum, “A ditadura que nao diz seu nome”, acceso el 12 de junio de 2020, https://brasil.elpais.com/brasil/2014/03/31/opinion/1396269693_200037.html. Véase en español Eliane Brum, "La dictadura que no dice su nombre”, acceso el 12 de junio de 2020, https://paraquenoserepitalahistoria.blogspot.com/2014/04/la-dictadura-que-nodice-su nombre.html. 
mundial: pensar los "indios" - esto es, todas las minorías étnicas- como "pobres" o pensar los "pobres" como "indios" y actuar políticamente en esta dirección. Porque pobre es un concepto "mayor", pobre es un subconjunto de la Mayoría, definido por la Mayoría; pobre es un concepto de Estado - un concepto, justamente, "estadístico"- Pero sucede que la inmensa mayoría estadística de esa mayoría pobre es minoría étnica, minoría política, minoría sexual, minoría racial. Pues en Brasil todo mundo es indio, excepto quien no es. ¿Y quién no es? Aquellos que la hechicería capitalista y la máquina colonial consiguieron transformar en "pobres", o aquellos que quieren hacer a los pobres un poquito menos pobres, justo lo necesario para que ellos puedan, como buenos trabajadores de un país que va hacia el frente aceleradamente, ${ }^{38}$ comprar (a crédito, es claro) el celular o el televisor que importamos de China. Pero, antes de conseguirlo, aquí y “allá afuera”, transformar a todos los indios del mundo en pobres, los pobres se habrán transformado en indios. El mundo está mudando, y no en la dirección en la cual los herederos intelectuales de los siglos XIX y $\mathrm{xx}$ imaginaban.

\section{BibLIOGRAFÍA}

Austin, John Langshaw. How to Do Things with Words. Massachusetts: Harvard University Press, 1962.

Austin, John Langshaw. Cómo hacer cosas con palabras. Palabras y acciones. Madrid: Ediciones Paidós Ibérica, 1981.

Barreto, Henyo y Clarissa Presotti. "Três Poderes contra os direitos indígenas." Portal Ambiental, acceso el 20 de mayo de 2020. http://www.portalambiental. org.br/pa/noticias?id=134.

Brum, Eliane. "A ditadura que nao diz seu nome." El País, acceso el 12 de junio de 2020. https://brasil.elpais.com/brasil/2014/03/31/opinion/1396269693_2000 37.html.

${ }^{38}$ N. de T. “En Brasil, se llama ‘frente' o ‘frontera agrícola' al avance de la producción capitalista sobre espacios vacíos u ocupados por otros modos de producción. Las 'fronteras agrícolas' están ligadas generalmente a los latifundios y al mercado de tierras, todos ellos en el contexto actual del agro-negocio.” Véase Ernenek Mejía, “Autenticidades, indianidades y antropología. Horizontes entre México y Brasil”, Cultura y representaciones sociales, v. 8, n. 15 (septiembre 2013): 97-123. 
Brum, Eliane. "La dictadura que no dice su nombre." Para que no se repita la historia, acceso el 12 de junio de 2020. https://paraquenoserepitalahistoria.blogspot. com/2014/04/la-dictadura-que-no-dice-su nombre.html.

Carneiro da Cunha, Manuela ed. História dos Índios no Brasil. São Paulo: Companhia das Letras, 1992.

Centre for the Study of African Development, "Meeting of Experts on the Study of Ethno-development and Ethnocide in Africa, Ouagadougou, 1983." UNESDOC. http://unesdoc.unesco.org/images/0005/000557/055780EB.pdf.

Comisión Nacional de los Derechos Humanos, Declaración de las Naciones Unidas sobre los Derechos de los Pueblos Indígenas. México: Comisión Nacional de los Derechos Humanos, 2018. http://www.cndh.org.mx/sites/all/doc/cartillas/2015-2016/13-declaracion-pueblos-indigenas.pdf.

Commissão Pro-Indio. Cuadernos da Comissão Pró-Índio No. 1. São Paulo: Global Editora, 1979.

Facultad Latinoamericana de Ciencias Sociales. "Réunion d'experts sur l'ethno-développement et l'ethnocide en Amérique Latine, San José, 1981.” UNESDOC. http://unesdoc.unesco.org/images/0005/000507/050786eb.pdf.

Jaulin, Robert. La paz blanca. Introducción al etnocidio. Buenos Aires: Tiempo Contemporáneo, 1973.

Legros, Martin. "Eduardo Viveiros de Castro: 'Ce qui se passe au Brésil relève d'un génocide’.” Philosophie Magazine, acceso el 19 de mayo de 2020. https://www. philomag.com/articles/eduardo-viveiros-de-castro-ce-qui-se-passe-au-bresilreleve-dun-genocide.

Mejía, Ernenek. "Autenticidades, indianidades y antropología. Horizontes entre México y Brasil.” Cultura y Representaciones Sociales, v. 8, n. 15 (septiembre 2013): 97-123.

Nações Unidas. Declaração das Nações Unidas sobre os Direitos dos Povos Indígenas. Rio de Janeiro: Centro de Informação das Nações Unidas United Nations Information Centre-Rio de Janeiro, 2008. http://www.un.org/esa/socdev/unpfii/documents/DRIPS_pt.pdf.

Observatorio Plurinacional de Aguas. "Eduardo Viveiros de Castro: lo que está pasando en Brasil es un genocidio." Observatorio Plurinacional de Aguas, acceso el 20 de mayo de 2020. https://oplas.org/sitio/2020/05/20/eduardo-viveiros-de-castro-lo-que-esta-pasando-en-brasil-es-un-genocidio/.

Povos Indígenas No Brasil. “Convenção ort sobre Povos Indígenas e Tribais em países independentes n. 169.” Povos Indígenas No Brasil, acceso el 19 de octubre de 2020. https://pib.socioambiental.org/pt/C/direitos/internacional/convencao-oit-sobre-povos-indigenas-e-tribais-em-. 
Povos Indigenas no Brasil. "No Brasil, todo mundo é índio, exceto quem não é." Povos Indigenas no Brasil, acceso el 19 de mayo de 2020. http://pib.socioambiental.org/files/file/PIB_institucional/No_Brasil_todo_mundo_é_\%C3\% ADndio.pdf.

Presidência da República. "Lei No 12.711, de 29 de agosto de 2012." Planalto, acceso el 20 de mayo de 2020. http://www.planalto.gov.br/ccivil_03/_ato20112014/2012/lei/112711.htm.

Schmitt, Carl. The Nomos of the Earth in the International Law of the Jus Publicum Europaeum. Nueva York: Telos Press, 2003.

Solokovskii, Sergey y Valery Tishkov. "Ethnicity". En Encyclopedia of Social and Cultural Anthropology, ed. Alan Barnard y Jonathan Spencer, 190-192. Nueva York: Routledge, 1996.

Smith, Anthony D. "The Politics of Culture, Ethnicity and Nationalism." En Companion Encyclopedia of Anthropology, Humanity, Culture and Social Life, ed. Tim Ingold, 706-733. Nueva York: Routledge, 1994.

Wikipedia. "Robert Jaulin.” Wikipedia, acceso el 20 de mayo de 2020. https:// en.wikipedia.org/wiki/Robert_Jaulin\#The_concept_of_ethnocide.

Wikipedia. "Joseph Alois Schumpeter." Wikipedia, acceso el 12 de junio de 2020. https://es.wikipedia.org/wiki/Joseph_Alois_Schumpeter.

\section{SOBRE EL AUTOR}

Se doctoró en Antropología Social por la Universidade Federal do Rio de Janeiro (UFRJ) en 1984 y realizó su posdoctorado en la Université de Paris x en 1989. Desde el año 1978 es docente de etnología en el Museu Nacional UFRJ y profesor titular desde enero de 2012. Se ha desempeñado como profesor visitante en las universidades de Chicago (1991, 2004), Manchester (1994), Universidade de São Paulo (2003), Universidade Federal de Minas Gerais (2005-06). 